Check for updates

Cite this: Mater. Chem. Front., 2019, 3, 1097

Received 27th December 2018, Accepted 5th April 2019

DOI: 10.1039/c8qm00672e

rsc.li/frontiers-materials

\section{Novel fluorescent amphiphilic copolymer probes containing azo-tetraphenylethylene bridges for azoreductase-triggered release $\dagger$}

\author{
Xiaojie Yuan, ${ }^{a}$ Zhe Wang, ${ }^{a}$ Lishan Li, ${ }^{a}$ Jiawei Yu, ${ }^{a}$ Yuqing Wang, ${ }^{a}$ Hongkun Li, ${ }^{a}{ }^{a}$ \\ Jiandong Zhang, ${ }^{a}$ Zhengbiao Zhang, (D) ${ }^{* a}$ Nianchen Zhou*a and Xiulin Zhu ${ }^{\text {ab }}$
}

\begin{abstract}
Enzyme-sensitive amphiphilic polymers play an important role as smart materials in drug delivery and biological detection. Azobenzene, an azoreductase active site, has received significant attention in recent years. Herein, we synthesized a novel aggregation-induced emission (AIE) fluorescent probe of amphiphilic block copolymer PCL-TPE-Azo-PEG based on an azoreductase response, in which tetraphenylethylene (TPE) conjugated to an azo group provides the junction between the hydrophilic and hydrophobic (PEG and $\mathrm{PCL}$ ) chain segments. In phosphate buffer solution, the resulting amphiphilic polymers self-assembled into rod-like micelles that are non-fluorescent owing to the quenching effect of the azo moieties on the AIE activity of TPE. In the presence of a reducing agent (such as azoreductase or $\mathrm{Na}_{2} \mathrm{~S}_{2} \mathrm{O}_{4}$ ), the azo bond was broken and the assemblies fragmented into PEG and PCL chain segments. Following disassembly of the micelles, the AIE effect of TPE was activated because the TPE moiety is encapsulated in the resulting PCL aggregation. Furthermore, the amphiphilic polymer could encapsulate drugs, such as DOX, to form drugloaded micelles in PB solution. And the micelles indicated an increasing fluorescence with drug release under the action of reducing agent. This amphiphilic block copolymer could potentially be applied in biosensing and controlled drug delivery for colonic conditions.
\end{abstract}

\section{Introduction}

Stimuli-responsive materials can undergo changes in their structures or states in response to external stimuli, such as light, temperature, $\mathrm{pH}$, ionic strength, and enzymes, amongst others. In the last few decades, stimuli-responsive polymeric materials have attracted significant attention in sensing, drug delivery, and biotechnology owing to their versatile and dynamic material properties. ${ }^{1-8}$ Developing controlled assembly/ disassembly polymeric micellar nanostructures is becoming increasingly important in order to fulfill the requirements of a wide range of smart materials. ${ }^{1}$

Enzymes play an important role in living organisms. The concentrations of various enzymes in diseased cells and tissues

\footnotetext{
${ }^{a}$ Suzhou Key Laboratory of Macromolecular Design and Precision Synthesis, Jiangsu Key Laboratory of Advanced Functional Polymer Design and Application, State and Local Joint Engineering Laboratory for Novel Functional Polymeric Materials, College of Chemistry, Chemical Engineering and Materials Science,

Soochow University, Suzhou Industrial Park, Suzhou 215123, China.

E-mail:nczhou@suda.edu.cn, zhangzhengbiao@suda.edu.cn

${ }^{b}$ Global Institute of Software Technology, No 5. Qingshan Road, Suzhou National Hi-Tech District, Suzhou 215163, China

$\dagger$ Electronic supplementary information (ESI) available: Synthesis, calculation, characterization. See DOI: 10.1039/c8qm00672e
}

can be higher than normal, leading to high activity. As a result, the enzyme response at a specific site could be used to trigger drug delivery and controlled release under physiological conditions. ${ }^{9,10}$ Currently a popular approach is to encapsulate the drug in polymeric nano-assemblies and then disassemble the delivery carriers to afford release.

Azobenzene compounds not only have a well-known light response due to reversible cis-trans isomerization but are also redox-responsive because the azo double bond can be disrupted under reducing conditions (such as in the presence of azoreductase, $\mathrm{Na}_{2} \mathrm{~S}_{2} \mathrm{O}_{4}$, or hydrazine). Azoreductase is primarily found in the human intestine and plays an important role in a number of processes. Azobenzene is an artificial enzyme active site that is attracting increasing research interest. ${ }^{11-25}$

In recent years, azoreductase-responsive amphiphilic block copolymers have attracted significant attention owing to their facile self-assembly in selected solvents to form nanoparticles with various morphologies. ${ }^{11-19}$ Khan et al. successfully prepared a series of nanoparticles composed of diblock copolymers with azobenzene side chains or as a bridge. ${ }^{16,17,21}$ Gao et al. prepared polymeric vesicles with good stability through the self-assembly of poly(glycidyl methacrylate) with grafted hydrophobic azobenzene and hydrophilic cyclodextrins. The azo bond was broken by $\mathrm{Na}_{2} \mathrm{~S}_{2} \mathrm{O}_{4}$ in a simulated colon chemistry environment, leading to 
the release of bovine serum protein from the cargo-loaded vesicles. $^{14}$

Fluorescent probes have shown to have an important role in the fields of bioimaging and biosensing owing to their efficiency and sensitivity. ${ }^{5,19,20,22-27}$ The emergence of enzymeresponsive fluorescent probes for drug delivery, the identification of enzymes, and biological imaging, has excited interest for various applications..$^{20,22-28}$ In recent years, fluorescence switches derived from azobenzene have attracted significant attention for their interesting stimuli-responsive properties. A useful design strategy is the use of pro-fluorophores containing an azo moiety as a fluorophore quenching unit, based on the concept of fluorescence resonance energy transfer (FRET) or the ultrafast azo-bond rotation mechanism. Fluorescence activation of the pro-fluorophores takes place through reductive cleavage of the azo moieties under stimulated redox conditions. $^{22-24,28-33}$ Some azo-based small molecule fluorescence probes have been studied and have shown promise for application in the fields of biosensing and bioimaging. Renard et al. modified a bio-reductive probe suitable for the detection of azoreductases by diazo coupling to connect azobenzene to rhodamine 110 dye (Rh110). Hanaoka et al. ${ }^{22,24,30}$ designed and synthesized a library of fluorescent probes based on azo rhodamine derivatives.

Over the last decade, fluorescent probes based on the aggregation-induced emission (AIE) effect have been successfully applied to in vivo cell imaging and enzyme activity determination. ${ }^{34,35}$ Tetraphenylethylene (TPE), a typical AIE chromophore, has been widely investigated owing to its high quantum yield and facile synthesis. Recently, He et al. prepared self-assembling aggregates containing azobenzene and TPE moieties through azo coupling reaction-induced macromolecular self-assembly, with enzyme-triggered fluorescent switching behaviors based on the FRET concept. ${ }^{23}$
Compared with small molecules, the molecular size of polymers can effectively reduce the absorption of the probe molecules, giving the polymer a higher cargo loading. Therefore, macromolecular fluorescent probes based on stimulus response have a broad range of potential applications. Various polymeric assembly-based azo reductions have been documented. However, to our knowledge, reports are limited for azo polymeric nanoparticles, either as controlled delivery carriers or biosensors.

In this work, we designed and prepared a small molecule pro-fluorophore with a TPE-azo moiety based on azo reduction response and AIE, in which an azobenzene group is directly conjugated to the TPE. This small molecule was then used as a scaffold for the fabrication of a macromolecular fluorescence probe. The amphiphilic block copolymer PCL $\mathrm{Ck}_{3 \mathrm{k}}$-TPE-Azo-PEG ${ }_{5 \mathrm{k}}$, which had a bridging TPE-azo moiety to connect the hydrophilic and hydrophobic chain segments. It was efficiently produced using a Cu-catalyzed azide/alkyne cycloaddition (CuAAC) "click" reaction by connecting hydrophilic segments (PEG) and hydrophobic segments (PCL) to the small molecule. The synthetic route to $\mathrm{PCL}_{n}$-TPE-Azo-PEG $m$ is outlined in Scheme 1. The resulting amphiphilic block copolymer could self-assemble in PB solution to form rod-like micelles, which were non-fluorescent as the azo moieties quenched the TPE fluorescence. In the presence of the reducing agent, the azo bond was broken, resulting in disassembly of the micelles. The AIE effect of TPE was activated because the TPE moiety after the broken azo bond was encapsulated in the regenerating PCL aggregation. Furthermore, the amphiphilic polymer was able to encapsulate drugs such as DOX, to form drug-loaded micelles, resulting in an increased fluorescence with drug release. Azoreductase exists predominantly in the human colon, and therefore this amphiphilic block copolymer has shown potential for application in biosensing and controlled drug release in the colon.
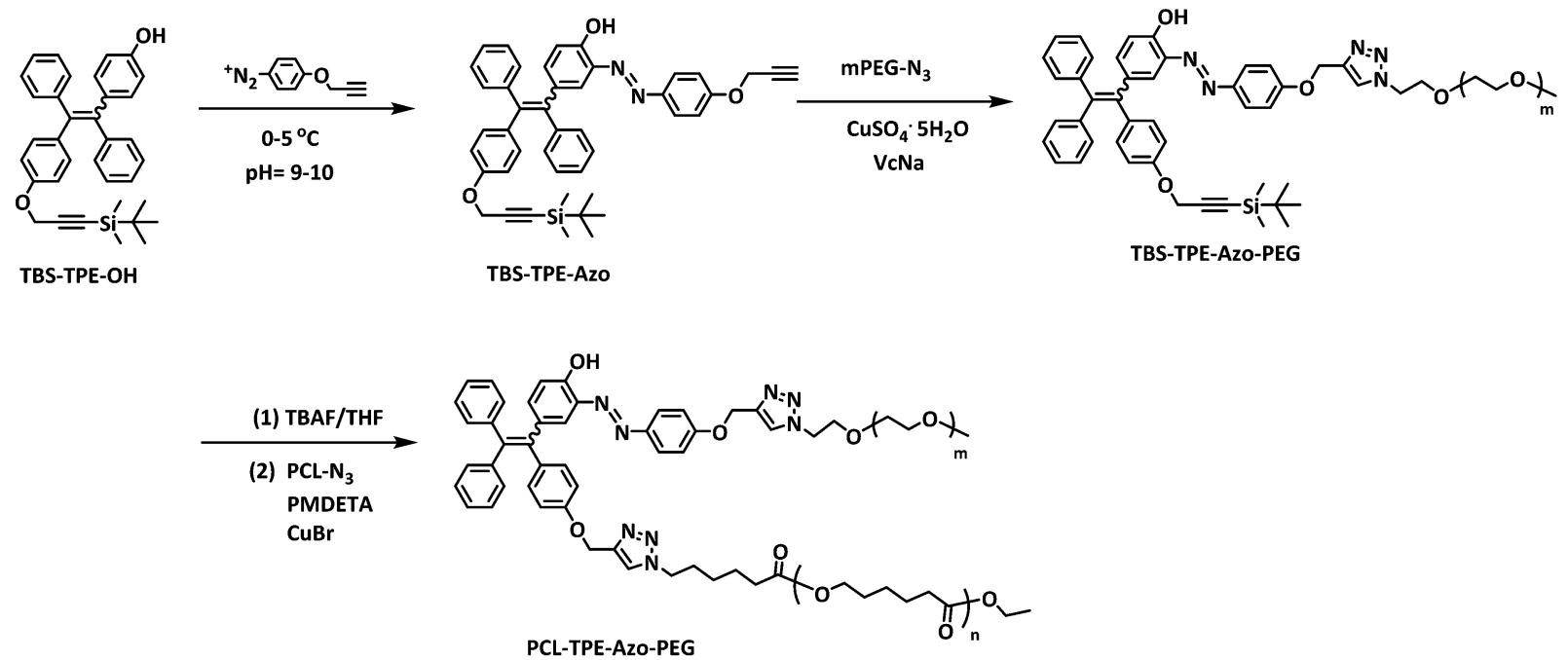

$P_{3 k}-T_{P E}-A z O-P E G_{5 k}: m=113, n=25$

Scheme 1 Synthetic routes of the block copolymer PCL $L_{n}-\mathrm{TPE}-\mathrm{Azo}-\mathrm{PEG}_{m}$. 


\section{Materials}

$N, N, N^{\prime}, N^{\prime \prime}, N^{\prime \prime}$-Pentamethyldiethylenetriamine (PMDETA; 98\%, J\&K) was dried with $4 \AA$ molecular sieves and then distilled under vacuum. Copper(I) bromide (CuBr) was purified by washing with acetic acid, water, and ethanol, dried under vacuum. Zinc dust (99.99\% trace metals basis, 600 mesh, Aladdin), 4-hydroxylbenzophenone (98\%, Energy Chemical), titanium tetrachloride $\left(\mathrm{TiCl}_{4}\right.$, AR, Enox), tetrabutylammonium fluoride (TBAF; $1.0 \mathrm{~mol} \mathrm{~L}^{-1}$ in tetrahydrofuran (THF), Energy Chemical), tetrahydrofuran (THF, AR, Enox), dimethylformamide (DMF; AR, Enox), polyethylene glycol monomethyl ether mesylate with $M_{\mathrm{n}}$ of $5000 \mathrm{~g} \mathrm{~mol}^{-1}$ Sigma-Aldrich), sodium azide (99.5\%, Aldrich), 6-bromohexanoylchloride, and 3-bromo-1-(tert-butyldimethylsilyl)-1-propyne were used as received. $\varepsilon$-Caprolactone ( $\varepsilon$-CL, AR, Aladdin) and stannous octoate $\left(\mathrm{Sn}(\mathrm{Oct})_{2}, 95 \%\right.$, Aldrich) were purified using distillation from calcium hydride under reduced pressure prior to use. Ethanol, (95+\%, Enox) was purified by distillation from anhydrous $\mathrm{MgSO}_{4}$ under reduced pressure prior to use. Nile Red was purchased from J\&K. Doxorubicin hydrochloride (DOX.HCl, 99\%) was purchased from Sigma. Azoreductase (DT-diaphorase human (NQO 1)) and coenzyme NADPH ( $\beta$-nicotinamide adenine dinucleotide phosphate reduced tetra(cyclohexylammonium) salt) were purchased from Sigma-Aldrich. The synthetic route to the new copolymer is shown in Scheme 1 . The syntheses of $\mathrm{mPEG}_{5 \mathrm{k}}-\mathrm{N}_{3}$ and $\mathrm{PCL}_{3 \mathrm{k}}-\mathrm{N}_{3}$ are given in the ESI. $\dagger$

\section{Synthesis of TBS-protected-alkyne-azobenzene unimer TBS-TPE-Azo}

The coupling reaction was as follows: TBS-TPE-OH (3.10 g, $6.00 \mathrm{mmol}$ ) and $10 \mathrm{~mL}$ tetramethylene oxide (THF) were added to a $25 \mathrm{~mL}$ beaker. A solution of the diazonium salt of 4-(prop-2ynyloxy)aniline (al- $\mathrm{N}_{2}$, synthesis given in the ESI $\dagger$ ) was then added to the beaker dropwise, slowly with stirring at $0-5{ }^{\circ} \mathrm{C}$. The $\mathrm{NaOH}$ solution was then added to adjust the $\mathrm{pH}$ of the coupling solution to 9-10. The final mixture was stirred for another $4 \mathrm{~h}$ and then extracted with ethyl acetate. The organic layer was dried using anhydrous $\mathrm{Na}_{2} \mathrm{SO}_{4}$ and evaporated under vacuum. The crude product was purified by column chromatography on silica gel (ethyl acetate/petroleum ether (V/V = 1:20-1:25) to obtain TBS-TPE-Azo $(0.67 \mathrm{~g}, 17 \%)$. This compound was characterized by ${ }^{1} \mathrm{H}$ NMR. ${ }^{1} \mathrm{H}$ NMR $\left(300 \mathrm{MHz}, \mathrm{CDCl}_{3}\right): \delta_{\mathrm{H}}(\mathrm{TMS}, \mathrm{ppm})=7.80-7.75$ (dd, 2H), 7.57-7.54 (dd, 1H), 7.12-6.92 (m, 15H), 6.76-6.70 (m, 3H), $4.76(\mathrm{~d}, 2 \mathrm{H}), 4.61(\mathrm{~d}, 2 \mathrm{H}), 2.55(\mathrm{t}, 1 \mathrm{H}), 0.90-0.87(\mathrm{~d}, 9 \mathrm{H}), 0.09-0.07$ (d, 6H) (Fig. S2, ESI†).

\section{Synthesis of PCL $_{3 \mathrm{k}}$-TPE-Azo-PEG $5 \mathrm{k}$}

A typical synthesis of $\mathrm{PCL}_{3 \mathrm{k}}$-TPE-Azo-PEG ${ }_{5 \mathrm{k}}$ was as follows: a mixture of $448 \mathrm{mg}$ TPE-Azo-PEG ${ }_{5 \mathrm{k}}$ and $120 \mathrm{mg} \mathrm{PCL}_{3 \mathrm{k}}-\mathrm{N}_{3}$ in $6 \mathrm{~mL}$ of dried anhydrous toluene was added to a $25 \mathrm{~mL}$ Schlenk flask. $42 \mathrm{mg}$ of $\mathrm{CuBr}$ and $72 \mu \mathrm{L}$ of PMDETA were then added to the flask. The mixture was degassed using three freeze/pump/thaw cycles and stirred for $24 \mathrm{~h}$ at $60{ }^{\circ} \mathrm{C}$. Subsequently, the solution was stirred with ion exchange resin for $24 \mathrm{~h}$ to remove the copper salts, then filtered and evaporated under reduced pressure to obtain the concentrated product. The concentrated solution was then slowly dripped into cold anhydrous ether. An orange solid was obtained after drying under high vacuum. The crude product was further purified with Pre-SEC to obtain the amphiphilic copolymer (yield: $28 \%, M_{\mathrm{n}, \mathrm{NMR}}=8900 \mathrm{Da}$, $\left.M_{\mathrm{n}, \mathrm{SEC}}=12100 \mathrm{Da}, M_{\mathrm{w}} / M_{\mathrm{n}}=1.02\right) .{ }^{1} \mathrm{H} \mathrm{NMR}\left(300 \mathrm{MHz}, \mathrm{CDCl}_{3}\right):$ $\delta_{\mathrm{H}}(\mathrm{TMS}, \mathrm{ppm})=8.23(\mathrm{~s}, 1 \mathrm{H}), 7.80-7.75(\mathrm{dd}, 2 \mathrm{H}), 7.57-7.54(\mathrm{dd}$, $1 \mathrm{H}), 7.12-6.96(\mathrm{~m}, 15 \mathrm{H}), 6.78-6.70(\mathrm{dd}, 3 \mathrm{H}), 5.43(\mathrm{~s}, 2 \mathrm{H}), 5.27(\mathrm{~s}$, $2 \mathrm{H}), 4.67(\mathrm{t}, 2 \mathrm{H}), 4.57(\mathrm{dd}, 2 \mathrm{H}), 4.08-4.04(\mathrm{dt}, 50 \mathrm{H}), 3.90(\mathrm{t}, 2 \mathrm{H})$, $3.70-3.60(\mathrm{~m}, 452 \mathrm{H}), 3.38(\mathrm{~s}, 3 \mathrm{H}), 2.33-2.28(\mathrm{t}, 50 \mathrm{H}), 1.70-1.60$ (m, 96H), 1.43-1.33 (m, 50H), 1.28-1.23 (m, 3H) (Fig. S4, ESI $\dagger$ ).

\section{Self-assembly of PCL $_{3 \mathrm{k}}$-TPE-Azo-PEG ${ }_{5 \mathrm{k}}$ in PB (phosphate buffered) solution $(\mathrm{pH}=7.4)$}

Self-assembly was typically conducted as follows: the $\mathrm{PCL}_{3 \mathrm{k}^{-}}$ TPE-Azo-PEG ${ }_{5 \mathrm{k}}$ amphiphilic polymer was first dissolved in DMF at an initial concentration of $5 \mathrm{mg} \mathrm{mL} \mathrm{mL}^{-1}$. PB solution $(50 \mathrm{mM}$, $\mathrm{pH}$ 7.4) was then added to the solution at a rate of $0.2 \mathrm{~mL} \mathrm{~h}^{-1}$ with stirring steadily to obtain the stable micelles. After dialyzing the micelles against PB solution (50 mM, pH 7.4) using dialysis tubing (MWCO 3500) to remove the organic solvent, transmission electron microscopy (TEM) and dynamic light scattering (DLS) were used to characterize the micelle morphology.

\section{Determination of the critical aggregation concentration (CAC)}

Nile red, a hydrophobic fluorescent dye, was selected as the fluorescent probe for determination of the critical aggregation concentration (CAC) of the amphiphilic block copolymer. By measuring the fluorescence intensity of Nile red in a series of different concentrations of micelle solution $\left(1.0 \times 10^{-3}-1.0 \times 10^{-1} \mathrm{mg} \mathrm{mL}^{-1}\right)$, the CAC could be easily established. The final concentration of Nile red in each sample was maintained at $5 \times 10^{-6} \mathrm{M}$. The fluorescence emission at 580-700 $\mathrm{nm}$ was monitored with excitation at $550 \mathrm{~nm}$. The CAC was estimated at the intersection point by extrapolating the intensity $I_{630}$ of the low and high concentration zones.

\section{Reduction response and fluorescence variation of micelles}

The enzyme azoreductase (DT-diaphorase, human) was dispersed in $\mathrm{PB}$ (phosphate buffer) solution $\left(1 \mathrm{mg} \mathrm{mL}{ }^{-1}, \mathrm{pH}\right.$ 7.2-7.4). Then the solution $(0.2 \mathrm{~mL})$ was added into freshly prepared self-assembled solution $(1.0 \mathrm{~mL})$ of PCL $_{3 \mathrm{k}}$-TPE-Azo$\mathrm{PEG}_{5 \mathrm{k}}$ in PBS. After that, the reduction reaction was initiated by the addition of co-enzyme NADPH solution $(1.0 \mathrm{~mL})$ in PBS $\left(1 \mathrm{mg} \mathrm{mL}{ }^{-1}\right)$. The reaction mixture was stirred at $37^{\circ} \mathrm{C}$ for $24 \mathrm{~h}$ to $48 \mathrm{~h}$ under argon atmosphere and placed at room temperature for 3 days. Meanwhile, $\mathrm{Na}_{2} \mathrm{~S}_{2} \mathrm{O}_{4}$ was also used to break the azo bonds. Under anaerobic conditions, $0.5 \mathrm{mg}$ of $\mathrm{Na}_{2} \mathrm{~S}_{2} \mathrm{O}_{4}$ was added to $3 \mathrm{~mL}$ of self-assembled micelles in PB solution $\left(0.3 \mathrm{mg} \mathrm{mL}^{-1}\right)$ at $37^{\circ} \mathrm{C}$.

Fluorescence spectrophotometry was then used to monitor the change in fluorescence intensity of the micelle solution. The effective breaking of azo bonds in the assembly was demonstrated by TEM and UV-vis spectroscopy.

\section{DOX loading of micelles}

The following process was carried out in the dark. A mixture of $5.0 \mathrm{mg}$ DOX. $\mathrm{HCl}$ and $3.6 \mu \mathrm{L}$ of triethylamine (TEA) in $1.0 \mathrm{~mL}$ of 
dimethyl sulfoxide (DMSO) was added to a $2 \mathrm{~mL}$ ampoule. After stirring overnight, excess TEA was removed by rotary evaporation to obtain the hydrophobic DOX solution. $4 \mathrm{~mL}$ of $\mathrm{PB}$ solution (50 mM, pH 7.4) was added dropwise to the mixture of copolymer in DMF $\left(1.0 \mathrm{~mL}, 5 \mathrm{mg} \mathrm{mL}^{-1}\right)$ and DOX base solution $\left(50 \mu \mathrm{L}, 5.0 \mathrm{mg} \mathrm{mL}^{-1}\right)$ with stirring at room temperature. Afterwards, in order to remove both unencapsulated DOX and the organic solvent, the mixture was dialyzed against $\mathrm{PB}$ solution (50 mM, pH 7.4) for $24 \mathrm{~h}$.

The amount of DOX was determined by fluorescence (FL4600) measurement (excitation at $480 \mathrm{~nm}$ ). Firstly, a calibration curve was obtained by measuring the fluorescence intensity of DOX/DMSO solutions with different concentrations. Secondly, the fluorescence intensity of DOX-loaded micelles dissolved in DMSO was analyzed. The amount of DOX loaded in the micelles could be determined using the calibration curve.

The drug loading content (DLC) and drug loading efficiency (DLE) were calculated using the following formulas:

DLC $(w t \%)=($ weight of loaded drug/weight of

$$
(\text { polymer }+ \text { loaded drug) }) \times 100 \%
$$

DLE (wt\%) = (weight of loaded drug/weight of drug in feed $)$

$$
\times 100 \%
$$

\section{Cytotoxicity tests}

The cytotoxicity of the blank micelles was evaluated using Caco2 human colon cancer cells and the MTT method. The (3-(4,5-dimethylthiazol-2-yl)-2,5-diphenyltetrazolium bromide) (MTT reagent) was added to the Caco2 human colon cancer cells. The cells were then incubated with blank micelles with a range of concentrations from 10 to $200 \mu \mathrm{g} \mathrm{mL}{ }^{-1}$ for $72 \mathrm{~h}$.

\section{Characterization}

Proton nuclear magnetic resonance $\left({ }^{1} \mathrm{H}\right.$ NMR) spectra were recorded on a Bruker $300 \mathrm{MHz}$ nuclear magnetic resonance (NMR) instrument using $\mathrm{CDCl}_{3}$ or DMSO- $\mathrm{d}_{6}$ as the solvent with tetramethylsilane (TMS) as the internal standard. The ${ }^{1} \mathrm{H}$ NMR spectra were referenced to $\delta 7.26 \mathrm{ppm}$ in $\mathrm{CDCl}_{3}$ or $\delta 2.50 \mathrm{ppm}$ in DMSO- $\mathrm{d}_{6}$. The number average molecular weight $\left(M_{\mathrm{n}}\right)$ and molecular weight distribution $\left(M_{\mathrm{w}} / M_{\mathrm{n}}\right)$ of the obtained polymers were determined using a size exclusion chromatograph (SEC) TOSOH HLC-8320 equipped with both refractive-index and UV detectors. Two TSKgel Super Mutipore HZ-N ( $3 \mu \mathrm{m}$ bead size) columns with a molecular weight range of 500-190000 Daltons were used, calibrated with narrow-distribution PS standard samples. THF was used as the eluent at a flow rate of $0.35 \mathrm{~mL} \mathrm{~min}{ }^{-1}$ operated at $40{ }^{\circ} \mathrm{C}$. An Agilent PL-50 reparative SEC system equipped with a manual injector was used to purify the crude polymers. THF was used as the eluent at a flow rate of $3 \mathrm{~mL} \min ^{-1}$. Separations were obtained using a PLgel $10 \mu \mathrm{m}$ MIXED-D, $300 \times 25 \mathrm{~mm}$ preparative SEC column maintained at $40{ }^{\circ} \mathrm{C}$. Each composition was determined using the TOSOH HLC-8320 SEC column as described above. Fourier transform-infrared (FT-IR) spectra were recorded on a Bruker
TENSOR-27 FT-IR spectrometer using the KBr disc technique. Ultraviolet visible (UV-vis) absorption spectra of the polymer solution were measured on a Shimadzu UV-2600 (Kyoto, Japan). The fluorescence emission spectra were obtained on a HITACHI F-4600 fluorescence spectrophotometer at room temperature. The TEM images were recorded on a HITACHI HT7700 TEM operating at a voltage of $120 \mathrm{kV}$. Before measurement, the samples were prepared by dropping the freshly dialyzed assembly solution onto a carbon-covered copper grid. After drying in air at room temperature, the samples were negatively stained with $1.0 \mathrm{wt} \%$ phosphotungstic acid. Hydrodynamic diameter $\left(D_{\mathrm{h}}\right)$ was determined by DLS using a Brookhaven NanoBrook 90Plus PALS instrument at $25{ }^{\circ} \mathrm{C}$ with a scattering angle of $90^{\circ}$.

\section{Results and discussion}

\section{Optimized configurations and UV-vis spectra of TBS-TPE-Azo}

To better understand the novel azobenzene-containing TPE-azo, in which an azo group is directly conjugated to the TPE, we simulated and calculated the optimized structures of the cis/trans isomers of TBS-TPE-Azo and their dipole moments and energies. The details are described in the ESI $\dagger$ (Scheme S2, Fig. S1, Tables S1 and S2). The UV-vis spectrum of TBS-TPE-Azo in THF was contrasted with that of TPE-2OH (Fig. S3, ESI $\dagger$ ). Following the conjugation of the azo moiety, the absorption peak in TBS-TPE-Azo, corresponding to TPE, underwent a red shift from $320 \mathrm{~nm}$ to $360 \mathrm{~nm}$. This shift was not observed for TPE-2OH because of the extension of the conjugate structure.

\section{Fluorescence characterization of TBS-TPE-Azo}

The fluorescence of TBS-TPE-Azo was investigated in detail by contrasting with TPE-2OH. As shown in Fig. 1(a), when the initial solutions of both TPE-2OH and TBS-TPE-Azo in THF were excited at $360 \mathrm{~nm}$, no fluorescence was detected because TPE is non-fluorescent in good solvents. However, as water was added to the THF solution (the water content reached $90 \%$ in the THF/water mixture), the TPE-2OH showed strong fluorescence emission around 450-500 $\mathrm{nm}$ owing to the AIE activity of TPE in the aggregated state. On the contrary, the TBS-TPE-Azo still showed no fluorescence, indicating no AIE behavior.
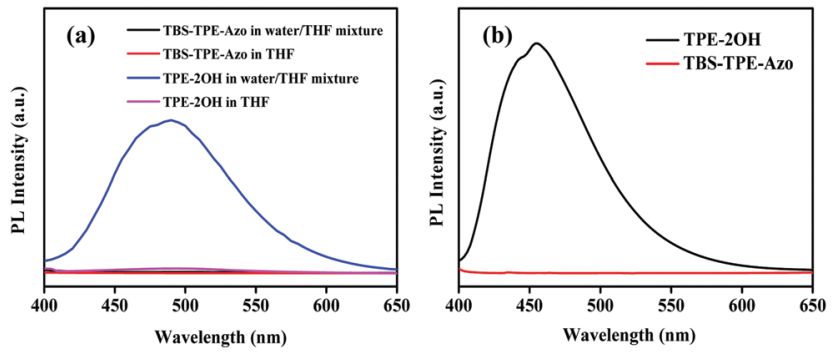

Fig. 1 (a) Fluorescence spectra of TBS-TPE-Azo and TPE-2OH in THF and water/THF mixture with a water fraction of $90 \%\left(\lambda_{\mathrm{ex}}=360 \mathrm{~nm}\right)$. All concentrations were $5 \times 10^{-5} \mathrm{~mol} \mathrm{~L}^{-1}$. (b) Fluorescence emission spectra of TBS-TPE-AzO and TPE-2OH in the solid state $\left(\lambda_{\mathrm{ex}}=395 \mathrm{~nm}\right)$. 
It is well known that the azobenzene chromophore is non-fluorescent in solution owing to ultrafast conformational changes around the $\mathrm{N}=\mathrm{N}$ bond after photoexcitation. ${ }^{22,28,31}$ However, when azobenzene chromophores are conformationally strained, such as in aggregates or when ring-strained, hampering their main nonradiative relaxation, azobenzene compounds can show intense fluorescence emission. ${ }^{36-39}$ To better understand the mechanism for the azo group quenching to TPE fluorescence in the aggregated state, we studied the emissions of TBS-TPE-Azo and TPE-2OH in the solid state (Fig. 1(b)). No TBS-TPE-Azo fluorescence was observed. We speculate that no fluorescence emission of TBS-TPE-Azo in the solid state or aggregated state may be related to the mechanisms of intramolecular photo-induced electron transfer or intramolecular electronic energy transfer. More investigation is needed to determine the exact reason. ${ }^{40-44}$

\section{Synthesis and characterization of amphiphilic block copolymer PCL $_{3 k}$-TPE-Azo-PEG $5 k$}

Based on the fluorescence characterization of TBS-TPE-Azo, we used TBS-TPE-Azo as a scaffold to fabricate a macromolecular fluorescent probe. This probe was based on AIE as the fluorescence would be "on" when the azo bond was broken by reduction in the aggregated state. As shown in Scheme 1, we first explored the synthesis of TBS-TPE-Azo using the traditional method of diazo coupling. TBS-TPE-Azo has two alkyne end groups to facilitate easy reaction with various amphiphilic block polymers that have different hydrophilic and hydrophobic segments. PCL $_{3 \mathrm{k}}$-TPE-Azo$\mathrm{PEG}_{5 \mathrm{k}}$ was obtained via CuAAC reaction of $\mathrm{mPEG}_{5 \mathrm{k}}-\mathrm{N}_{3}$ and $\mathrm{PCL}_{3 \mathrm{k}}-\mathrm{N}_{3}$ with TBS-TPE-Azo in succession.

${ }^{1} \mathrm{H}$ NMR, FT-IR and SEC curves conformed the successful synthesis of the amphiphilic block copolymers (Fig. S4 and S5, ESI, $\dagger$ Fig. 2). Symmetric SEC elution curves and a significant shift of the SEC curves of both $\mathrm{PCL}_{3 \mathrm{k}}-\mathrm{N}_{3}$ and TPE-Azo-PEG ${ }_{5 \mathrm{k}}$ to PCL $_{3 \mathrm{k}}$-TPE-Azo-PEG $5 \mathrm{k}$ were observed (Fig. 2). In addition, the disappearance of the azide peak at $2100 \mathrm{~cm}^{-1}$ and alkynyl peak at $3300 \mathrm{~cm}^{-1}$ was observed by FT-IR (Fig. S5, ESI $\dagger$ ), which suggested that the click reaction had successfully completed. The molecular weight of PCL $_{3 \mathrm{k}}$-TPE-Azo-PEG ${ }_{5 \mathrm{k}}$ and the block ratio of the hydrophilic chain segment $(m)$ and hydrophobic chain segment $(n)$, were obtained by ${ }^{1} \mathrm{H}$ NMR (Fig. S4, ESI $\dagger$ ) and eqn (S1), (S2) and (S3) (ESI $\dagger$ ), $m / n=113 / 25$.

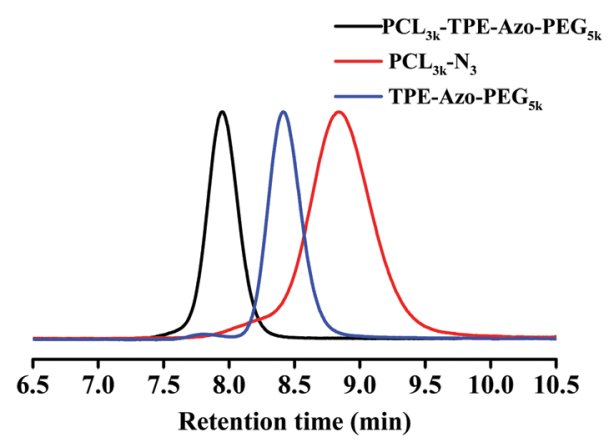

Fig. 2 SEC traces of PCL $L_{3 k}-T P E-A z o-P E G_{5 k}, P C L_{3 k}-N_{3}$ and TPE-Azo-PEG $G_{5 k}$.
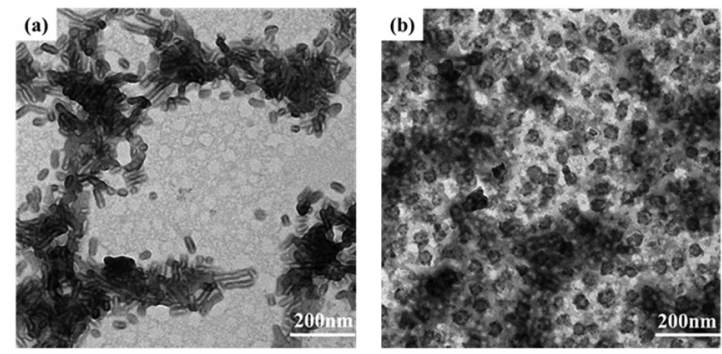

Fig. 3 TEM images of (a) PCL $3 k-T P E-A z o-P E G_{5 k}$ micelles before azoreductase treatment and (b) after azoreductase treatment for $48 \mathrm{~h}$.

Self-assembly of $P_{C} \mathrm{~L}_{3 \mathrm{k}}$-TPE-Azo-PEG ${ }_{5 \mathrm{k}}$ in $\mathrm{PB}$ solution $(\mathrm{pH}=7.4)$

The self-assembly of $\mathrm{PCL}_{3 \mathrm{k}}$-TPE-Azo-PEG ${ }_{5 \mathrm{k}}$ was initiated in a mixture of DMF and water by carefully tuning the experimental parameters. The critical aggregation concentration (CAC) in PB solution was determined using the hydrophobic dye Nile red as a fluorescent probe, based on a previously reported method, ${ }^{18}$ and was found to be about $32 \mathrm{mg} \mathrm{L}{ }^{-1}$ for PCL $_{3 \mathrm{k}}$-TPE-Azo-PEG $\mathrm{Fk}_{5 \mathrm{k}}$ (Fig. S6, ESI $\dagger$ ). The size and morphology of the self-assembled aggregates formed by the amphiphilic block copolymer in PB solution, were characterized by TEM (Fig. 3(a) and Fig. S8(a), ESI $\dagger$ ) and DLS (Fig. S7 and S9(a), ESI $\dagger$ ). As shown in the TEM images, the amphiphilic block copolymer formed stable nanorod micelles.

\section{Reduction response of micelles and reductant-activated AIE fluorescence}

Based on the literatures, ${ }^{11,17}$ enzyme azoreductase can fully induce the cleavage of the azobenzene units in micelles solution of the amphiphilic diblock copolymer with an azobenzene linkage. In this work, azoreductase and dithionate sodium hydrosulfite $\left(\mathrm{Na}_{2} \mathrm{~S}_{2} \mathrm{O}_{4}\right)$ were used as the reducing agent to investigate the reduction responsiveness and activated-AIE fluorescence of self-assembled micelles of $\mathrm{PCL}_{3 \mathrm{k}}$-TPE-azo-PEG ${ }_{5 \mathrm{k}}$, respectively. The morphologies and sizes of the degradation products above were detected by TEM and DLS (Fig. 3(b) and Fig. S7, S8(b), S9(b), ESI $\dagger$ ). AS shown in Fig. 3(b), the short rod-like micelles were dissociated and regenerated spherical aggregates of diameter about 40-60 nm and larger aggregates as a result of the interruption of the azo bond. The hydrophobic block PCL re-aggregated into spherical aggregates after the azo bond fracture. The aggregates further combined to form large aggregates due to the lack of hydrophilic block to stabilize the aggregates. The aggregates precipitated after being placed for a period of time. It can also be verified from the DLS data (Fig. S7, ESI $\dagger$ ), which show obvious difference between the sizes of aggregates before and after the enzymatic hydrolysis.

Fluorescence intensity was measured at different time intervals after the addition of the reducing agent (excitation wavelength, $360 \mathrm{~nm}$ ). The intensity of the fluorescence emission of micelle solution around $500 \mathrm{~nm}$ increased significantly after the treatment of reducing agent (Fig. 4(a and c)). By tracking the UV-vis spectra of the enzyme degradation solution, the absorption peaks of the azobenzene of TPE-Azo at around $365 \mathrm{~nm}$ distinctly weakened after reduction for $48 \mathrm{~h}$ (Fig. 4(b)). The results make it 

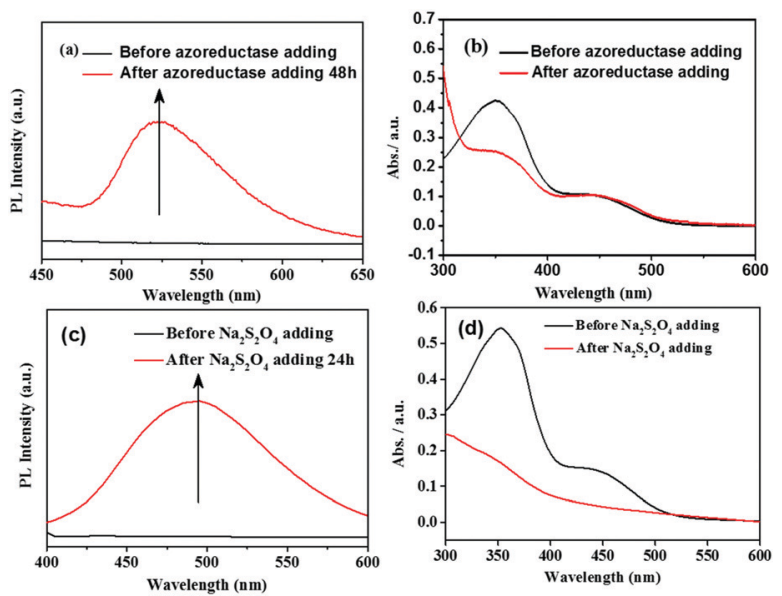

Fig. 4 (a) Fluorescence intensity variation for the micelles of $P \mathrm{PL}_{3 \mathrm{k}}-\mathrm{TPE}-$ Azo-PEG 5 in PB solution before (black) and after (red) the enzyme treatment for $48 \mathrm{~h}$ in the presence of azoreductase $\left(0.16 \mathrm{mg} \mathrm{mL}^{-1}\right.$ of $\mathrm{PCL}_{3 \mathrm{k}}-\mathrm{TPE}-\mathrm{AzO}-$ $P E G_{5 k}$ in PB solution, at $37^{\circ} \mathrm{C}$ ), $\lambda_{\mathrm{ex}}=360 \mathrm{~nm}$. (b) UV-vis spectra of the micelles of $\mathrm{PCL}_{3 k}-\mathrm{TPE}-\mathrm{Azo}-\mathrm{PEG}_{5 \mathrm{k}}$ in PB solution before (black) and after (red) the enzyme treatment. (c) Fluorescence intensity variation for the micelles of $\mathrm{PCL}_{3 k}$-TPE-Azo-PEG $\mathrm{F}_{5 k}$ in PB solution before and after the $\mathrm{Na}_{2} \mathrm{~S}_{2} \mathrm{O}_{4}$ treatment for $24 \mathrm{~h}\left(0.1 \mathrm{mg} \mathrm{mL}^{-1}\right.$ of $P \mathrm{PC}_{3 \mathrm{k}}-\mathrm{TPE}-\mathrm{AzO}-\mathrm{PEG}_{5 \mathrm{k}}$, at $\left.37^{\circ} \mathrm{C}\right)$. (d) UV-vis spectra of the micelles of $\mathrm{PCL}_{3 \mathrm{k}}-\mathrm{TPE}-\mathrm{AzO}-\mathrm{PEG}_{5 \mathrm{k}}$ in $\mathrm{PB}$ solution $\left(0.1 \mathrm{mg} \mathrm{mL}^{-1}\right)$ before (black line) and after (red) the $\mathrm{Na}_{2} \mathrm{~S}_{2} \mathrm{O}_{4}$ treatment for $24 \mathrm{~h}$.

clear that azoreductase is capable of efficiently cleaving the azo bonds of PCL-TPE-Azo-PEG in micelles solution, led to the significant increase in fluorescent emission. Nevertheless, the weaker absorption peak around $365 \mathrm{~nm}$ was still observed from the enzyme degradation product of micelles solution in UV-vis spectra. This should be attributed to small amounts of incomplete reduction of azo bonds from TPE-azo after the enzymolysis. Contrasting UV-vis spectra of the degradation product of micelles solution in the presence of $\mathrm{Na}_{2} \mathrm{~S}_{2} \mathrm{O}_{4}$ (Fig. 4(d)), the absorption peaks of azobenzene of TPE-Azo completely disappeared after reduction reaction. The disappearance of azobenzene indicated that the reducing agent of small molecule such as $\mathrm{Na}_{2} \mathrm{~S}_{2} \mathrm{O}_{4}$ was more effective for the azo bond reduction compared with macromolecular enzyme.

In order to explore the efficiency of the enzymatic catalytic action on the self-assembling micelles of PCL Pk $_{3}$-TPE-Azo-PEG $5 \mathrm{k}$, control experiments, i.e., the enzymolysis of aqueous solution of TPE-Azo-PEG ${ }_{5 k}$ containing PEG hydrophilic segments were conducted under equal conditions as the enzymolysis of micelles solution. The variation of fluorescence intensity and absorption change before and after the enzyme treatment were measured by fluorescence and UV-vis spectra, as shown in Fig. S10 (ESI $\dagger$ ). The characteristic peaks of azobenzene in TPE-Azo after the enzyme treatment was also observed in UV-vis spectra, similar to the results of enzyme treatment of the PCL3k-TPE-Azo-PEG5k micellar solution. It was speculated that the direct connection of the propeller-like and bulky TPE moiety to azo bond could lead to a larger steric hindrance.

\section{Reduction-triggered drug release and fluorescence changes}

The reduction-triggered structural transformation gives rise to potential applications as encapsulation and release systems for colonic diseases. ${ }^{45}$ Here we focused on the "turn-on" fluorescence behavior for the fluorescent polymer probe during reductiontriggered drug delivery. The anticancer drug doxorubicin (DOX) was chosen as the model molecule for encapsulation. The selfassembly of PCL $_{3 \mathrm{k}}$-TPE-Azo-PEG ${ }_{5 \mathrm{k}}$ was conducted in PB solution in the presence of DOX. A typical encapsulation experiment is described in the Experimental section. DOX was loaded into micelles at a polymer concentration of $5.0 \mathrm{mg} \mathrm{mL}$. The PCL $_{3 \mathrm{k}}$-TPE-Azo-PEG ${ }_{5 \mathrm{k}}$ micelles showed DOX loading efficiencies of $41 \%$. The morphology of the micelles obtained in the presence of DOX was characterized by TEM, which revealed that stable rod-like micelles were produced (Fig. S13(a) and S14(a), ESI $\dagger$ ).

Reduction-triggered drug release studies in vitro were investigated at pH $7.4(\mathrm{~PB}, 50 \mathrm{mM})$ and $37{ }^{\circ} \mathrm{C}$ by using $\mathrm{Na}_{2} \mathrm{~S}_{2} \mathrm{O}_{4}$ and azoreductase that exists in the colon, respectively. A control experiment was carried out in the absence of reducing agent. After reduction for a specific time, the fluorescence emission of DOX was monitored at $480 \mathrm{~nm}$ excitation wavelength (Fig. S11, $\mathrm{ESI} \dagger)$. The fluorescence intensity of DOX at $\sim 590 \mathrm{~nm}$ decreased gradually owing to the release of hydrophobic DOX from the micelle carriers. The percentage release was calculated based on the fluorescence changes at $590 \mathrm{~nm}$. The percentage release profile was plotted as a function of time (Fig. 5(a and c)). As expected, the minimal DOX release was observed in the control experiment, which showed that the DOX-loaded polymer micelles were stable in the absence of a stimulus. DOX release from the micelles was markedly accelerated with time in the presence of $\mathrm{Na}_{2} \mathrm{~S}_{2} \mathrm{O}_{4}$, and the percentage release reached a maximum value (about 70\%) for $35 \mathrm{~min}$. The percentage release increased slowly with time in the presence of reductases. After enzyme treatment for $48 \mathrm{~h}$, the percentage release of DOX reached a maximum value (about $28 \%$ ). The percentage release of DOX in the presence of reductases is obviously less than that
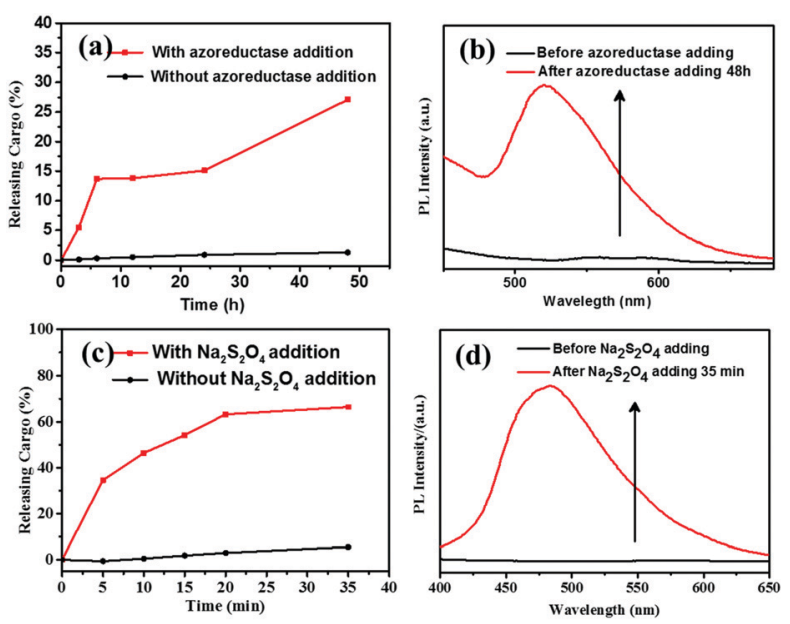

Fig. 5 Drug release profiles (a) fluorescence changes (b) for the DOXloaded micelles of $\mathrm{PCL}_{3 \mathrm{k}}$-TPE-Azo-PEG $\mathrm{Fk}_{5 \mathrm{k}}$ in $\mathrm{PB}$ solution during azoreductase treatment for different time periods $\left(0.1 \mathrm{mg} \mathrm{mL}^{-1} \mathrm{PCL}_{3 \mathrm{k}}-\mathrm{TPE}-\mathrm{Azo}_{\mathrm{z}} \mathrm{PEG}_{5 \mathrm{k}}\right.$ in PBS at $\left.37^{\circ} \mathrm{C}\right)\left(\lambda_{\mathrm{ex}}=360 \mathrm{~nm}\right)$. Drug release profiles (c) fluorescence changes (d) for the DOX-loaded micelles of $\mathrm{PCL}_{3 \mathrm{k}}-\mathrm{TPE}-\mathrm{AzO}-\mathrm{PEG}_{5 \mathrm{k}}$ in PB solution during $\mathrm{Na}_{2} \mathrm{~S}_{2} \mathrm{O}_{4}$ treatment for different time periods $\left(0.3 \mathrm{mg} \mathrm{mL}^{-1} \mathrm{PCL}_{3 \mathrm{k}^{-}}\right.$ TPE-Azo-PEG ${ }_{5 k}$ in PB at $\left.37{ }^{\circ} \mathrm{C}\right)\left(\lambda_{\text {ex }}=360 \mathrm{~nm}\right)$. 


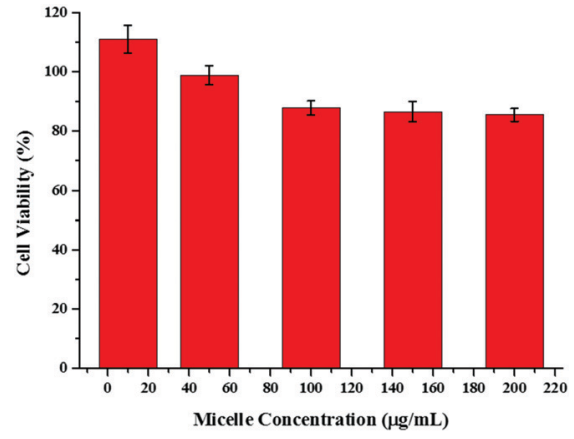

Fig. 6 Cytotoxicity of polymeric micelles against $\mathrm{Caco}_{2}$ human colon cancer cells at various concentrations.

in the presence of $\mathrm{Na}_{2} \mathrm{~S}_{2} \mathrm{O}_{4}$, which can be attributed that the macromolecular enzyme catalyst has a steric hindrance to enter into the micelles for the interruption of the azo bond compared with that of $\mathrm{Na}_{2} \mathrm{~S}_{2} \mathrm{O}_{4}$. The absorption and morphology of the DOX-loaded micelles during reduction were characterized by UV-vis spectroscopy and TEM. TEM images showed that the nanorod boundaries became blurred and gradually dissociated (Fig. S13 and S14, ESI $\dagger$ ). In addition, UV-vis spectra showed that the characteristic peak of azobenzene at $450 \mathrm{~nm}$ dissipated owing to the breaking of the azo double bonds (Fig. S12, ESI $\dagger$ ).

The fluorescence emission based on the TPE $\left(\lambda_{\mathrm{ex}}=360 \mathrm{~nm}\right)$ of the DOX-loaded micelles in PB solution was tested during the reduction release, as shown in Fig. 5(b and d). With increasing release time, the fluorescence intensity of the micelles solution distinctly enhanced after reduction reaction in the presence of $\mathrm{Na}_{2} \mathrm{~S}_{2} \mathrm{O}_{4}$ /azoreductase. Therefore, based on the "Latent fluorescence" concept, the Azo-TPE caged nanoparticles would be versatile in biosensing and bioimaging applications.

\section{Cytotoxicity tests}

The cytotoxicity of the blank micelles was evaluated using Caco2 human colon cancer cells and the MTT method. The results showed that the cell viability was $\sim 90 \%$, indicating that this type of block copolymer has good biocompatibility (Fig. 6).

\section{Conclusions}

We successfully synthesized a fluorescent amphiphilic block copolymer probe, PCL $_{3 \mathrm{k}}$-TPE-Azo-PEG $\mathrm{P}_{5 \mathrm{k}}$, based on an azo reduction response and AIE mechanism, using the CuAAC click reaction. The amphiphilic block copolymer can be selfassembled in $\mathrm{PB}$ solution $(\mathrm{pH}$ 7.4) to form nanorod like micelles with a hydrophobic interface of TPE-Azo, which is nonfluorescent as the azo moieties quench the AIE activity of TPE. Furthermore, the micelles can encapsulate hydrophobic model drugs such as DOX. Under reducing conditions, such as in the presence of enzyme azoreductase, the micelles disassembled owing to the disruption of the $\mathrm{N}=\mathrm{N}$ double bond. Increasing fluorescence was observed with the micelles dissociation because the AIE effect was activated by the reducer stimulus. Reduction-triggered drug release showed turn-on behavior of fluorescence for the polymer micelles during drug release. Thus, the amphiphilic block copolymer has revealed potential for application in biosensing and controlled drug release for colonic conditions. We anticipate that the valuable data in this work will provide new insights into the AIE mechanism and the reduction-responsiveness of TPE-azo containing derivatives, broaden the variety of macromolecular fluorescent probes based on AIE. Ongoing work to modulate the morphology and size of the drug-loaded assemblies is underway in our laboratory, in order to achieve better drug loading and more controlled release in the presence of azoreductase.

\section{Conflicts of interest}

There are no conflicts to declare.

\section{Acknowledgements}

The authors are grateful for financial support from the National Nature Science Foundation of China (21574090), the Priority Academic Program Development (PAPD) of Jiangsu Higher Education Institutions, and the Program of Innovative Research Team of Soochow University. The authors are very grateful for the kind supports on enzymolysis experiments provided by Prof. Yaning $\mathrm{He}$ at Tsinghua University, China.

\section{Notes and references}

1 D. Roy, J. N. Cambre and B. S. Sumerlin, Prog. Polym. Sci., 2010, 35, 278.

2 Z. Ge and S. Liu, Chem. Soc. Rev., 2013, 42, 7289.

3 E. Fleige, M. A. Quadir and R. Haag, Adv. Drug Delivery Rev., 2012, 64, 866.

4 C. De Las Heras Alarcon, S. Pennadam and C. Alexander, Chem. Soc. Rev., 2005, 34, 276.

5 J. N. Liu, W. Bu and J. Shi, Chem. Rev., 2017, 117, 6160.

6 X. F. Ji, Y. Li, H. Wang, R. Zhao, G. P. Tangb and F. H. Huang, Polym. Chem., 2015, 6, 5021.

7 G. C. Yu, M. M. Zhang, M. L. Saha, Z. W. Mao, J. Chen, Y. Yao, Z. J. Zhou, Y. J. Liu, C. Y. Gao, F. H. Huang, X. Y. Chen and P. J. Stang, J. Am. Chem. Soc., 2017, 139, 15940.

8 G. C. Yu, R. Zhao, D. Wu, F. W. Zhang, L. Shao, J. Zhou, J. Yang, G. P. Tang, X. Y. Chen and F. H. Huang, Polym. Chem., 2016, 7, 6178.

9 M. Zelzer, S. J. Todd, A. R. Hirst, T. O. McDonald and R. V. Ulijn, Biomater. Sci., 2013, 1, 11.

10 R. V. Ulijn, J. Mater. Chem., 2006, 16, 2217.

11 J. L. Wang, S. Li, B. Wu and Y. N. He, Eur. Polym. J., 2016, 84, 236.

12 A. D. Wong, A. L. Prinzen and E. R. Gillies, Polym. Chem., 2016, 7, 1871.

13 J. Wang, B. Wu, S. Li and Y. J. He, J. Polym. Sci., Part A: Polym. Chem., 2017, 55, 2450.

14 W. X. Gu, Q. L. Li, H. Lu, L. Fang, Q. Chen, Y. W. Yang and H. Gao, Chem. Commun., 2015, 51, 4715. 
15 A. D. Wong, T. M. Güngör and E. R. Gillies, ACS Macro Lett., 2014, 3, 1191.

16 J. Rao, C. Hottinger and A. Khan, J. Am. Chem. Soc., 2014, 136, 5872 .

17 J. Rao and A. Khan, J. Am. Chem. Soc., 2013, 135, 14056.

18 J. Lu, F. Zhou, L. Li, Z. Zhang, F. Meng, N. Zhou and X. Zhu, RSC Adv., 2016, 6, 58755.

19 M. Bates, B. Huang, G. T. Dempsey and X. Zhuang, Science, 2007, 317, 1749.

20 S. M. Borisov and O. S. Wolfbeis, Chem. Rev., 2008, 108, 423.

21 J. Rao and A. Khan, Polym. Chem., 2015, 6, 686.

22 W. Piao, S. Tsuda, Y. Tanaka, S. Maeda, F. Liu, S. Takahashi, Y. Kushida, T. Komatsu, T. Ueno, T. Terai, T. Nakazawa, M. Uchiyama, K. Morokuma, T. Nagano and K. Hanaoka, Angew. Chem., Int. Ed., 2013, 52, 13028.

23 S. Li, J. Wang, J. Shen, B. Wu and Y. He, ACS Macro Lett., 2018, 7, 437.

24 W. Piao, K. Hanaoka, T. Fujisawa, S. Takeuchi, T. Komatsu, T. Ueno, T. Terai, T. Tahara, T. Nagano and Y. Urano, J. Am. Chem. Soc., 2017, 139, 13713.

25 L. L. Lock, A. G. Cheetham, P. Zhang and H. Cui, ACS Nano, 2013, 7, 4924.

26 Y. Fan, F. Li and D. Chen, Biomaterials, 2014, 35, 7870.

27 R. Zhan, A. J. H. Tan and B. Liu, Polym. Chem., 2011, 2, 417.

28 A. Chevalier, P. Y. Renard and A. Romieu, Chem. - Asian J., 2017, 12, 2008.

29 N. Shin, K. Hanaoka, W. Piao, T. Miyakawa, T. Fujisawa, S. Takeuchi, S. Takahashi, T. Komatsu, T. Ueno, T. Terai, T. Tahara, M. Tanokura, T. Nagano and Y. Urano, ACS Chem. Biol., 2017, 12, 558.

30 S. Luo, Y. Liu, F. Wang, Q. Fei, B. Shi, J. An, C. Zhao and C. H. Tung, Analyst, 2016, 141, 2879.
31 A. Chevalier, C. Mercier, L. Saurel, S. Orenga, P. Y. Renard and A. Romieu, Chem. Commun., 2013, 49, 8815.

32 N. J. Rattray, W. A. Zalloum, D. Mansell, J. Latimer, C. H. Schwalbe, A. J. Blake, E. V. Bichenkova and S. Freeman, Chem. Commun., 2012, 48, 6393.

33 K. Kiyose, K. Hanaoka, D. Oushiki, T. Nakamura, M. Kajimura, M. Suematsu, H. Nishimatsu, T. Yamane, T. Terai, Y. Hirata and T. Nagano, J. Am. Chem. Soc., 2010, 132, 15846.

34 Y. Hong, J. W. Y. Lam and B. Z. Tang, Chem. Soc. Rev., 2011, 40, 5361.

35 A. Qin, J. W. Y. Lam and B. Z. Tang, Prog. Polym. Sci., 2012, 37, 182.

36 M. Hammerich, C. Schutt, C. Stahler, P. Lentes, F. Rohricht, R. Hoppner and R. Herges, J. Am. Chem. Soc., 2016, 138, 13111.

37 M. Han and M. Hara, J. Am. Chem. Soc., 2005, 127, 10951.

38 Y. Li, N. Zhou, W. Zhang, F. Zhang, J. Zhu, Z. Zhang, Z. Cheng, Y. Tu and X. Zhu, J. Polym. Sci., Part A: Polym. Chem., 2011, 49, 4911.

39 Q. Bo and Y. Zhao, Langmuir, 2007, 23, 5746.

40 Y. Liu, Y. Yu, J. W. Lam, Y. Hong, M. Faisal, W. Z. Yuan and B. Z. Tang, Chem. - Eur. J., 2010, 16, 8433.

41 S. Speiser, Chem. Rev., 1996, 96, 1953-1976.

42 W. K. Feng, Y. Y. Feng, S. F. Wang, W. Feng, W. H. Yi and Q. H. Gong, Chin. Phys. B, 2010, 19, 113401.

43 T. Ueno, Y. Urano, K. i. Setsukinai, H. Takakusa, H. Kojima, K. Kikuchi, K. Ohkubo, S. Fukuzumi and T. Nagano, J. Am. Chem. Soc., 2004, 126, 14079.

44 J. Huang, Y. Wu, H. Fu, X. Zhan, J. Yao, S. Barlow and S. R. Marder, J. Phys. Chem. A, 2009, 113, 5039.

45 S. Q. Gao, Z. R. Lu, B. Petri, P. Kopeckova and J. Kopecek, J. Controlled Release, 2006, 110, 323. 